\title{
11-Nor-Delta9-THC-9-Carboxylic Acid Measurement
}

National Cancer Institute

\section{Source}

National Cancer Institute. 11-Nor-Delta9-THC-9-Carboxylic Acid Measurement. NCI

Thesaurus. Code C142293.

The determination of the amount of 11-nor-delta-9-THC-9-carboxylic acid present in a sample. 